88 Meerschaum. - Reiner kohlens. Kalk. - Eine Norerde existirt nicht.

\title{
Der Meerschaum
}

zur Pfeifenfabrikation stammt aus Klein-Asien (Natolien), wo er bei dem Dorfe Killtschik in der Nähe des Städtchens EskiSheher am Flusse Sakarija (39'N. Br. $48^{\circ}$ O. L.) gegraben wird. Er enthält $\mathrm{SiO}^{2}=90,9, \mathrm{MgO}=27,24, \mathrm{HO}=11,68$, Spec. Gew. Proc. 1,13-1,6. Wenigor werthvoller Meerschaum findet sich bei Hrubschütz und Oslovan in Mähren, Vallecas und Toledo in Spanien, Sebastopol und Kaffa in der Krim, anf der Insel Negroponte und bei Theben in Griechenland.

Ruhla liefert jährlich 25,000 Dutzend echte, in Wachs oder Oel gesottene Meerschaumköpfe und 92,376 Dutzend unechte. (Polytechn. Notizblatt). Dr. Reich.

\section{Darstellung von reinem kohlensauren Kalk.}

Nach Gräger digerirt man in Hydrat verwandelten gebrannten Kalk mit einer nicht ganz zureichenden Mlenge von in Wasser gelöstem salpetersauren Ammoniak. Der halk wird gelöst und die Lösung enthält neben salpetersaurem Kalk freies $\Lambda$ mmoniak, während die Verunreinigungen nicht in Iösung gehen. Leitet man durch die erhaltene ammoniakalische Lösung einen Strom von Kohlensüuregas, so fällt aller Kalk als schweres krystallinisches Pulver nieder. Damit sicher aller Kalk gefällt werde, setat man der Vorsicht halbor der Flüssigkeit noch etwas kohlensaures Ammoniak hinzu, worauf man den Niederschlag auf ein Filter bringt, auswäscht und trocknet. (Neues Jahrb. f. Pharm. Mäzheft 1868.). Dr. Schacht.

\section{Fine Norerde existirt nicht.}

Nach Sranberg's Angaben (Ch. Centralbl. 1845. S. 640) sollte die Zirkonerde keine einfache Erde sein, sondern aus einem Gemenge von reiner Zirkonerde, mit einer neuen Erde, die er Norerde nannte, bestehen. Untersuchungen anderer Chemiker haben über die Existenz dieser Erde Zweifel aufkommen lassen. Jetzt hat R. Kermann diesen Gegenstand von Neuem aufgenommen und ist zu folgenden Resultaten gekommen: 